\title{
Hibridismo na música instrumental do Grupo Medusa: Associação de gêneros musicais distintos em Pé no chão
}

\author{
Guilherme Araújo Freire (UNICAMP, Campinas, SP) \\ guilhermefreirea@gmail.com
}

Rafael dos Santos (UNICAMP, Campinas, SP)
rdsantos@unicamp.br

Resumo: Na década de 1980, o jazz fusion tinha grande repercussão internacional. Baseando-se na mistura das linguagens musicais do jazz com outros gêneros, o estilo incorporava construções harmônicas modais associadas ao uso da tecnologia a favor de uma busca a novos timbres. No Brasil, era visto como símbolo de modernidade e considerado como vanguarda musical pela crítica especializada, influenciando sensivelmente grupos de música instrumental. Este estudo tem como foco a produção musical do Grupo Medusa, formado na cidade São Paulo por músicos instrumentistas renomados do cenário da música popular brasileira. Através da análise dos aspectos rítmicos, melódicos, harmônicos e estruturais da música Pé no Chão, pretende-se compreender o modo pelo qual o Grupo Medusa articula elementos da linguagem musical de gêneros populares brasileiros e norte-americanos, obtendo uma sonoridade hibrida e, buscando também identificar apropriações de procedimentos musicais do fusion realizadas.

Palavras-chave: hibridismo; música popular; música instrumental; Grupo Medusa.

\section{Hybridism in the Instrumental Music of the Medusa Group: Association of Different Musical Genres in Pé no chão}

\begin{abstract}
In the 1980s, jazz fusion had great international repercussion. Based on the mix of musical languages of jazz with other genres, this style incorporated modal harmonic constructions associated with the use of technology in order to search for new timbres. In Brazil, it was seen as a symbol of modernity and considered by critics as being a musical forefront, influencing significantly instrumental music groups. This study focuses on the musical production of the Medusa Group, formed in São Paulo by renowned Brazilian popular musicians. The purpose of this article is to understand, through a rhythmic, melodic, harmonic and structural analysis of the song Pé no Chão (Feet on the Ground), the way in which the Group Medusa blends musical elements of Brazilian and American popular styles, obtaining an hybrid sound. It also tries to identify appropriations of musical procedures from fusion, performed in the song.
\end{abstract}

Keywords: hybridism; popular music; instrumental music; Brazilian Medusa Group.

\section{1 - Introdução}

Ana Maria Bahiana escreveu em 1979, um dos poucos artigos da época analisando a trajetória do segmento de música instrumental no periodo. Ela afirma que para compreender em perspectiva a produção da música instrumental, é preciso considerar que o termo genérico 'música instrumental' não se referia à toda forma musical executada apenas por instrumentos, mas sim "às formas musicais cunhadas na informação do jazz e à geração de seus praticantes, instrumentistas dispersos no mercado após a fase da bossa nova com o desinteresse do mercado e da indústria fonográfica" (BAHIANA, 1979, p.61).

Assim, notamos que para a jornalista, nas práticas do que era conhecido como música instrumental nos anos 70, já se subtendia certo conhecimento do jazz pelos músicos. Em seguida, a autora define a bossa nova como uma fase musical de "depuração da síntese jazz/samba", caracterizando-a como uma "fase de refinamento harmônico e improviso" que consagrou uma grande quantidade de instrumentistas e que, com o advento da canção de protesto - em que supostamente havia "absoluta predominância da fala e do texto" -, passaram a acompanhar cantores ou buscar espaço no exterior.

Após o período dos festivais, Bahiana afirma que se iniciou uma gradual modificação do mercado, especificamente partir de 1976/77, vitalizado em geral, com o crescimento do interesse do público pelo segmento de música instrumental. Contando com uma maior receptividade, uma nova produção e legitimação de alguns artistas, a música instrumental toma uma retomada expressiva com uma nova forma, distinta do período de jazz/bossa. 
Segundo a autora, essa revitalização da música instrumental aconteceu com a formação de um público constituída de jovens que tinham seu gosto em grande parte formado pela liberdade de improviso do rock progressivo, mais aproximado do jazz, ou seja, um público com certa sensibilidade para apreciar seções instrumentais e solos de longa duração. Ana Maria Bahiana ainda sustenta: "não seria exagero afirmar que grande parte do público que tornou possivel a existência de uma atividade constante da música improvisada, no Brasil, seja constituida por roqueiros desiludidos com os sucedâneos nacionais de sua música" (BAHIANA, 1979, p.63). Corroborando a afirmação de Ana Maria Bahiana, o jornalista Souza escreve, em 1976, que "[o rock] pode levar um tipo de público jovem condicionado - e careta, no sentido inverso - a interessar-se por música instrumental, valorizar os músicos, procurar ouvir com maior atenção o que dizem os sons, independentes da mensagem direta das letras" (SOUZA, 1979, p.205).

Uma pontuação do interesse do público nesse segmento no período foi a realização do $1^{\circ}$ Festival de Jazz de São Paulo - Montreaux em 1978, que reuniu mais de setenta mil pessoas e tiveram várias apresentações de artistas brasileiros como Egberto Gismonti, Hermeto Pascoal, Nivaldo Ornellas, Djalma Corrêa, Luiz Eça, Hélio Delmiro, Márcio Montarroyos, Wagner Tiso, Vitor Assis Brasil, Zimbo Trio, e de músicos jazzistas consagrados como John McLaughlin, Chick Corea, Larry Coryell e George Duke. Sobre o festival, Muller (2005) aponta uma matéria na qual a mídia comenta sobre a repercussão do evento: "foi um grande sucesso sob qualquer ângulo de análise e acabou se transformando num evento musical sem paralelo na história não apenas da cidade de São Paulo, mas de todo o país" (NEVES, 1978).

Para Ana Maria Bahiana, um índice claro da força que a música instrumental adquire naquele momento é o surgimento e consolidação de alguns nomes de grande importância no segmento: Egberto Gismonti e Hermeto Pascoal, os mais destacados. A razão do destaque argumentada pela autora está na qualidade e persistência de sua produção junto ao público. Para a autora, o diferencial nos trabalhos desses músicos estava no "rompimento com a cadeia jazz/bossa" - de onde tiveram grande parte de sua formação musical e aperfeiçoamento técnico -, passando a incorporar elementos da música considerada "de raiz".

Havia na época também outra forma de romper com a 'cadeia jazz/bossa', identificada por Bahiana nos trabalhos de Wagner Tiso. Segundo a autora, o artista vivenciou uma transformação de sua música, passando de uma estética ligada fortemente ao jazz e à bossanova (ainda na década de 60), em direção a "uma língua musical híbrida de clássico, música regional e uma pitada de rock" (BAHIANA, 1979, p.65). Não apenas Wagner Tiso, mas a partir de certo momento de sua carreira, Egberto Gismonti também passa a incorporar à música brasileira, procedimentos da música erudita e da fusão jazzística com o rock, estilo conhecido como fusion.
Fusion é um termo usado para referir-se à modalidade híbrida de jazz surgido na virada da década de 60 para 70. Foi desenvolvido a partir da associação da rítmica do funk e rythm and blues, com a amplificação e processadores de efeitos (distorção, reverb, etc) do rock e métricas de compasso oriundas de músicas não ocidentais. 0 repertório apresenta músicas predominantemente instrumentais e exigem geralmente um alto nível de proficiência no instrumento para execução. A autoria da invenção do novo estilo é indeterminada, pois surgiram paralelamente vários albuns com características hibridas de jazz e rock, como o do grupo Free Spirits de Larry Coryell ou o Charles Lloyd Quartet. Entretanto, o álbum que foi consagrado pela 'inauguração' do estilo é Bitches Brew de Miles Davis. Neste disco, participaram John McLaughlin, Chick Corea, Joe Zawinul e Wayne Shorter, artistas que, posteriormente, em carreira solo ou em atividade com seus grupos, estariam entre os protagonistas principais do estilo.

0 novo estilo manteve grande popularidade em seu país de origem durante a década de 70 e início da década de 80. No Brasil, teve um impacto bastante significativo: os festivais de jazz de 1978 e 1980 trouxeram grandes nomes para apresentações no país. Segundo Muller (2005, p.88), muitos grupos instrumentais brasileiros que emergem neste período incorporam elementos do estilo fusion, tanto o uso dos instrumentos e efeitos eletrônicos, como na abordagem e composição harmônica de suas músicas. Além do Grupo Medusa, podemos citar também artistas como o próprio Egberto Gismonti, Airto Moreira, a Banda Metalurgia e o grupo Cama de Gato, que também incorporaram elementos do fusion.

\section{2 - Grupo Medusa}

0 grupo de música instrumental Medusa foi formado em São Paulo, reunindo alguns dos músicos mais requisitados do cenário de música popular brasileira. 0 grupo durou aproximadamente três anos e teve dois álbuns lançados em sua trajetória.

0 primeiro álbum, intitulado Grupo Medusa, foi lançado em 1981 como o primeiro lançamento do selo Som da Gente, pequena gravadora independente que direcionou a maior parte de sua produção ao segmento da música instrumental. A formação do grupo nesse álbum era: Amilson Godoy (piano, clavinet), Cláudio Bertrami (baixo elétrico, contrabaixo acústico), Heraldo do Monte (guitarra, violão e bandolim) e Chico Medori (bateria e percussão), com participações de Theo da Cuíca e Jorginho Cebion na percussão. Grupo Medusa é composto por músicas autorais, com bastante espaço para improvisos, harmonias sofisticadas, presença marcante de ritmos brasileiros e percussão.

Após o lançamento do álbum, realizaram uma turnê pelo Brasil e se apresentaram no $3^{\circ}$ Festival de Jazz em Paris, em 1982. No ano de 1983, lançaram seu segundo disco Ferrovias, também pelo selo Som da Gente e com algumas mudanças na formação: o guitarrista Olmir Stocker, também conhecido como "Alemão", entrou no lugar de Heraldo do 
Monte e o percussionista Theo da Cuíca foi integrado à formação. 0 disco segue a mesma linha estética do primeiro álbum, apresentando uma composição de Olmir Stocker, uma releitura do choro Lamento de Pixinguinha, maior volume de instrumentos de percussão e maior destaque para a cuíca, que além de ter função rítmica exerce também singela função melódica nos arranjos do disco.

Apesar da trajetória do grupo apontar para um relativo sucesso e conquista do seu espaço no mercado, inclusive com apresentações internacionais, sua trajetória teve curta duração. 0 grupo se desfez após um aneurisma sofrido por Bertrami em meados da década de 80 que paralisou seu lado esquerdo integralmente.

\section{3 - Entre a fusão musical e a preservação das "raízes"}

Partindo da suposição de que o artista, ainda que tenha absoluta autonomia nas escolhas estéticas e na concepção do trabalho, direciona sua produção para se consolidar e legitimar dentro do mercado; compreender as escolhas e o sentido da ação pelo qual os músicos podem ter seguido ainda que inconscientemente, constitui uma maneira de compreender como o grupo chegou à sonoridade presente nos discos. Diante da grande repercussão do fusion na década de 70 no mercado internacional, apropriar-se de seus procedimentos musicais constituía uma maneira de distinguir-se no mercado, pois o novo estilo era considerado pela crítica musical como "vanguarda do jazz".

No Grupo Medusa essas apropriações eram realizadas, mas aparentemente de maneira limitada. Foi publicado um texto no encarte do primeiro disco do Grupo Medusa, que tem autoria de Amilson Godoy e que traz questões importantes para compreender as escolhas estéticas realizadas. Segue sua transcrição:

\footnotetext{
"Existe um conflito básico em quem nasce em um país colonizado culturalmente; a gente não se ouve mais, a memória se apaga, as coisas de fora nos são impostas e acabam sendo consumidas como autênticas. 0 Grupo Medusa é resultado desse conflito. 0 colonizado pode até aprender com o colonizador, mas não pode jamais deixar de pensar com a própria cabeça. Nosso trabalho tem uma proposta musical sem preconceitos ou barreiras, cujo objetivo maior é conseguir uma fusão musical sem perder o vínculo com nossas raizes. As diferentes origens, o universo de informações, a vivência, as experiências anteriores, os espaços conquistados por cada um dos componentes do grupo, fez com que acontecesse uma integração tamanha, que nós quatro viramos um. Um grupo de música instrumental brasileira".
}

Logo no início do discurso, já se faz referência à oposição colônia/colonizador levantando a questão do imperialismo cultural ("as coisas de fora nos são impostas") e a questão de se evitar a suposta dependência (" 0 colonizado pode até aprender com o colonizador, mas não pode jamais deixar de pensar com a própria cabeça") relativa aos países imperialistas. Nota-se que existe um envolvimento nacionalista claro na música do grupo, questão constante não apenas no universo musical, como também, amplamente, nos debates culturais nos mais diversos períodos. Em seguida, quando o grupo define sua proposta como "sem preconceitos ou barreiras", fica evidente a questão: até que ponto é legítimo para o grupo, o diálogo da cultura brasileira com as formas culturais estrangeiras?

A solução seria então, promover uma fusão musical mantendo o vínculo com as raízes brasileiras, ou seja, incorporar elementos da música estrangeira e, ao mesmo tempo, preservar caracteristicas da música brasileira considerada de 'raiz'. Ao utilizar o termo "fusão", faz-se referência ao estilo jazz fusion, que para o grupo parece ser fonte de inspiração de ideias propriamente musicais.

Como tentaremos demonstrar nas análises da música Pé no chão a seguir, o grupo incorpora sonoridades fusion, assumindo a mistura de gêneros distintos na construção de uma nova sonoridade. A referência às "raizes brasileiras" e à oposição colonizado/colonizador no discurso podem ser resquícios, em plena década de 80 , do ideário político nacional-popular, iniciado em parte através do projeto nacionalista do governo de Getúlio Vargas e amplamente difundido na sociedade brasileira da década de 60 .

\section{4 - Aspectos Estruturais de Pé no chão}

A música Pé no chão, presente no álbum Grupo Medusa, tem quatro minutos e quarenta e um segundos de duração, foi composta pelo baterista do grupo Chico Medori e apresenta a mesma instrumentação que é predominante no LP e se constitui de piano Fender, baixo Fender fretless, bateria, guitarra e percussão. Os instrumentos de percussão utilizados na faixa são: tamborins e cuíca.

A música apresenta uma apropriação feita pelo grupo do uso do Fender Rhodes', um instrumento norteamericano, utilizado no disco refencial Bitches Brew de Miles Davis e adotado também em outros discos do estilo. A escolha desse instrumento pelo pianista Amilson Godoy no disco já denota uma certa influência da estética do estilo jazz fusion.

0 uso de um instrumento com origem cultural estrangeira, quando associado à execução da rítmica sincopada do samba, tradicional da música brasileira se mostra como uma mistura de tradições culturais realizada pelo grupo. Ela não se aproxima nem das tradições brasileiras, nem das tradições norte-americanas.

A mistura estética dos diferentes estilos ganha maior evidência ainda com o uso dos instrumentos de percussão nos temas A e improviso de guitarra, que além de terem seus timbres consagrados na estética do samba, ressaltam a acentuação rítmica caracteristica da sonoridade do gênero (a questão da acentuação rítmica será mais detalhada em análise posterior).

Provavelmente o exemplo mais convincente da mistura feita pelo grupo nesta música estaria no Tema A, quando 
Amilson Godoy executa a melodia da seção no Fender Rhodes. Ao mesmo tempo em que obtém destaque no primeiro plano na música (de certa maneira, com timbre associado ao fusion), é acompanhado pelo ritmo sincopado e acentuado dos tamborins e cuíca, tradicionais da cultura brasileira.

No arranjo da música, as seções se organizam como mostra o Ex.1. A forma de Pé no chão baseia-se em uma estrutura quaternária simples $A-B-A-B$ com 36 compassos, que é precedida de uma introdução com oito compassos. Entre os dois grupos de exposições temáticas, ocorre o solo de guitarra com 32 compassos seguido de uma ponte com quatro compassos e por fim chegando ao desfecho da música no Tema $B^{\prime}$, que é uma versão modificada do Tema $B$, adaptada para conduzir ao fim da música.

Constata-se em sua forma um planejamento no uso das percussões dentre as seções, de modo que fossem alternadas as partes da música com percussão e as partes da música apenas com o quarteto tocando. Observando os quadros acima, percebe-se que mesmo quando duas seções têm percussão em sequência, uma delas possui breve duração.

Essa alternância causa efeito de contraste para o ouvinte quando há mudança temática, pois além da presença dos tamborins e da cuíca, existe a intenção por parte dos músicos de acentuar os contratempos das sincopas nas seções com percussão para caracterizar bem a rítmica do samba. Além disso, nas seções sem percussão tanto o acompanhamento rítmico como a melodia têm notas mais longas e menor subdivisão rítmica, o que confere assim um caráter mais estático à seção e acentua o contraste nas mudanças temáticas.

Desta maneira, ao realizar uma escuta do disco Grupo Medusa observamos que esse traço da alternância de seção com ênfase na rítmica de um gênero tradicional brasileiro seguida de uma seção com incorporação de procedimentos da música estrangeira não acontece apenas na música Pé no chão, mas também na maioria de suas faixas. Constitui assim, uma característica da sonoridade do grupo mesclar elementos da estética de linguagens musicais com origens culturais distintas utilizando a forma da música como meio de organizar os elementos e criar contrastes nas músicas.

Ainda atentando ao uso da percussão na música, observamos que após a segunda exposição do Tema B, Amilson Godoy executa uma frase blues no piano Fender (Ex.2), que combinada ao acompanhamento dos instrumentos de percussão característicos da tradição musical brasileira, efetua uma mistura cultural ao sobrepor um elemento melódico-harmônico tradicionalmente utilizado no jazz e no blues com a percussão da seção rítmica brasileira.

\begin{tabular}{|l|c|c|c|c|c|}
\hline $\begin{array}{l}\text { Introdução } \\
8 \text { compassos }\end{array}$ & $\begin{array}{c}\text { Tema A } \\
8 \text { compassos } \\
\text { (com percussão) }\end{array}$ & $\begin{array}{c}\text { Tema B } \\
8 \text { compassos }\end{array}$ & $\begin{array}{c}\text { Tema A } \\
8 \text { compassos } \\
\text { (com percussão) }\end{array}$ & $\begin{array}{c}\text { Tema B (casa II) } \\
12 \text { compassos }\end{array}$ & $\begin{array}{c}\text { Chamada 'bluesy'2 } \\
\text { do piano } \\
4 \text { compassos } \\
\text { (com percussão) }\end{array}$ \\
\hline $\begin{array}{l}\text { Improviso de } \\
\text { guitarra } \\
\text { 32 compassos } \\
\text { (com percussão) }\end{array}$ & $\begin{array}{c}\text { Ponte } \\
4 \text { compassos }\end{array}$ & $\begin{array}{c}\text { Tema A } \\
8 \text { compassos } \\
\text { (com percussão) }\end{array}$ & $\begin{array}{c}\text { Tema B } \\
8 \text { compassos }\end{array}$ & $\begin{array}{c}\text { Tema A } \\
8 \text { compassos } \\
\text { (com percussão) }\end{array}$ & $\begin{array}{c}\text { Tema B' final } \\
4 \text { compassos }\end{array}$ \\
\hline
\end{tabular}

Ex.1 - Tabela ilustrando disposição das seções na forma de Pé no chão (ler em sentido horizontal, da esquerda para a direita).
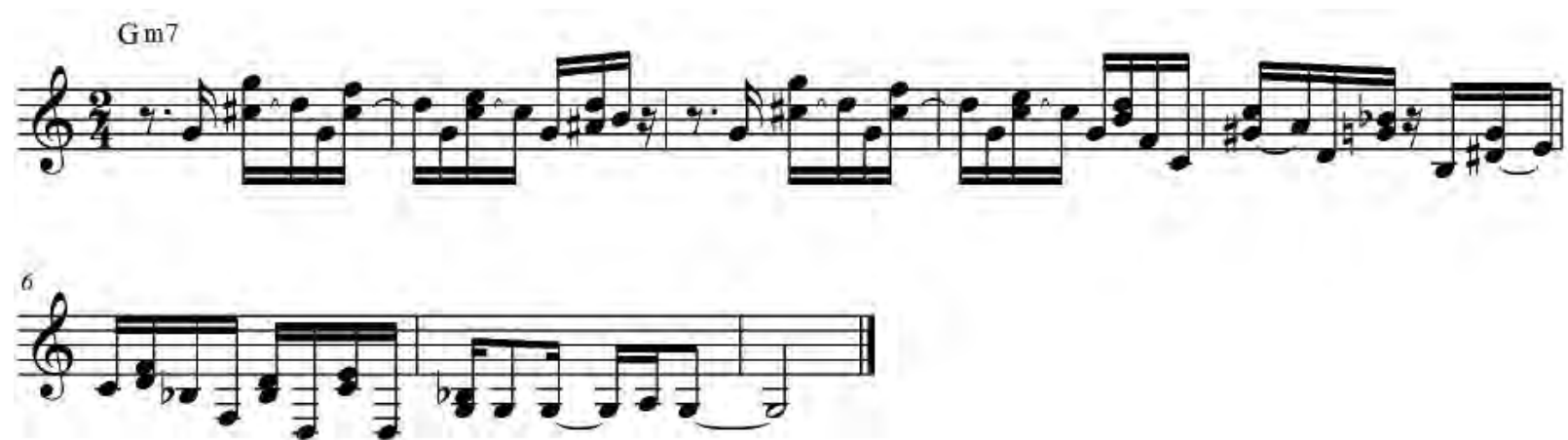

Ex.2 - Frase blues executada por Amilson Godoy 
Apesar de não haver uma alternância que distinga o caráter cultural dentre as seções e que aborde todos os planos da música, existe uma aparente predominância do plano rítmico no contraste gerado na alternância das seções, que torna-se evidente pela percussão e se constitui numa característica da sonoridade do grupo.

\section{5 - Aspectos Rítmicos}

A música inicia com o chimbau da bateria e 0 piano Fender executando uma frase baseada em semicolcheias apresentando já em sua execução, a acentuação característica do gênero, que ganha maior expressividade quando a cuica começa sua execução no quinto compasso da seção. Encerrada a introdução, a entrada dos tamborins reforça o caráter suingado das linhas da percussão no Tema $\mathrm{A}$ e remete à sonoridade de escola de samba.

A segunda seção temática (Tema B) inicia com uma alteração contrastante na execução do acompanhamento. Uma vez que no Tema $A$, a condução rítmica aparece bem delineada com linhas do gênero samba, os acordes do Tema B são executados e sustentados com notas longas, modificando o caráter de subdivisão rítmica (suingado), para uma textura rítmica menos dinâmica. Além dessa mudança de caráter, 0 Tema B tem, em sua estrutura, mudanças frequentes e rápidas de fórmula de compasso, alterando de compasso simples para compasso composto.

Assim, podemos afirmar que a seção rítmica do grupo constrói dois tipos de acompanhamento dentre as seções com caracteres distintos. Um deles mais pautado na linguagem do gênero samba, com maior dinamicidade, baseado em linhas-guia características e presença marcante da sincopa, ressaltada pela execução da percussão. 0 outro, mais pautado na estética do jazz, baseando-se em acentuações rítmicas da melodia, com maior uso de notas longas e ataques de pouca intensidade sonora.

Uma característica marcante no plano rítmico entre as seções é a presença marcante da execução de convenções. 0 uso das convenções não se limita aos Temas B e B', pois também são executadas nas exposições do Tema A. Mesmo em seções caracterizadas por notas longas, a bateria preenche os espaços entre as notas da melodia com frases próprias da linguagem do instrumento, o que confere um caráter percussivo à sonoridade do grupo.

\section{6 - Aspectos Harmônicos e Melódicos}

A apropriação de procedimentos musicais oriundos do jazz fica mais evidente quando atentamos aos planos harmônico e melódico de Pé no chão. Na primeira seção temática da música, apenas se utiliza um acorde - Gm7, o que constitui uma característica modal da harmonia da seção, pois a ausência da polaridade tensão/resolução esvazia a necessidade do retorno ou estabelecimento de um centro tonal (Ex.3).

Segundo Gridley (1988, p.71), no estilo de jazz conhecido como bebop, a harmonia era objetivamente determinada, com acordes e durações bem delimitadas antes da improvisação, quase sempre cercando um centro tonal, com tempo constante e fórmula de compasso predominantemente quaternária. Para escapar dessas convenções tradicionais referidas, Miles adotou quatro possibilidades como alternativas de escape que foram: 1) inventar uma progressão harmônica, que não precisaria ser simétrica ou tonal; 2) Seguir uma sequência pré-determinada de modos, com duração livre; 3) Seguir uma sequência pré-determinada de modos, com duração pré-determinada; 4) Basear-se uma improvisação inteira em um único modo.

Foram utilizadas todas as quatro possibilidades na gravação do álbum Kind Of Blue, que fez bastante sucesso, situando-o entre os mais importantes da história do jazz. Esse fato acabou transformando essa inovação estética em tendência nas gravações dos discos de jazz pós-1959, consolidando o caráter modal na harmonia, nos improvisos e composições do jazz em sua linguagem.

Em um trabalho que trata dos diferentes tipos de modalismos na história da música, o pesquisador Sérgio Freitas destaca que após o surgimento do modalismo jazzístico, este também passa a se mesclar com outras tendências das músicas populares do mundo e aponta o fenômeno de hibridação entre os modos e suas respectivas culturas: "relacionadas ou não com o jazz, outras práticas modais (...) com maior ou menor acento étnico, são perceptíveis agora quando os músicos populares se acham no direito de desterritorializar e reterritorializar todo tipo de escalas (chinesas, vietnamitas, húngaras, árabes, libanesas, eslavas, romenas, turcas, ciganas, hispânicas, ameríndias, nordestinas, modos orientais, etc.), que junto das incontáveis escalas sintéticas se mesclam aos modos diatônicos da catequese cristã ocidental" (FREITAS, 2008, p.271).

Tema A

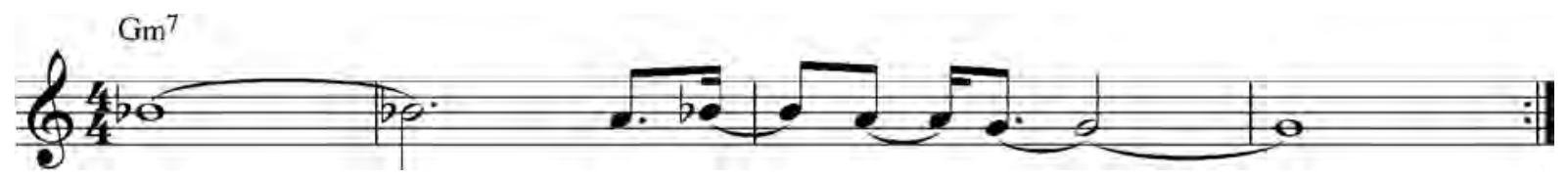

Ex.3 - Melodia e harmonia cifrada do Tema A de Pé no chão 
0 fato de que todo o tema se constrói em apenas um acorde e esse mesmo acorde é utilizado durante todo o improviso de guitarra, nos permite comparar com a música So What do disco acima citado. Ambas as músicas têm no Tema $\mathrm{A}$ e improvisos, harmonia baseada em um acorde só, evidência que denota uma apropriação feita pelo grupo da estética do jazz modal no processo composicional da música.

Além desse aspecto, notamos outra apropriação da mesma música presente na condução executada pela guitarra quando utiliza o mesmo voicing tocado pelo piano no disco de Miles Davis, só que transposto e adaptado à linguagem do samba (Ex.4).

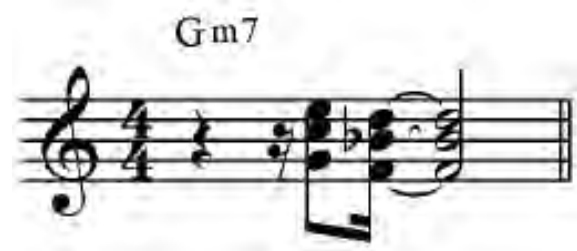

Ex.4 - Estrutura de acorde similar à de So What, contudo adaptado ritmicamente para o contexto de samba.

As apropriações da linguagem musical jazzística, ao mesmo tempo em que aproximam e criam diálogo com a cultura estrangeira, buscam se afastar da musicalidade norte-americana através da articulação de uma musicalidade brasileira. 0 exemplo 4 é um caso exemplar de uma apropriação que é idêntica em termos estrutura harmônica, mas articulada com a rítmica brasileira.
$\mathrm{Na}$ segunda seção temática da música encontramos também outras características modais em sua concepção harmônica. Segue abaixo sua transcrição:

Nessa seção (Ex.5), observamos que são utilizadas predominantemente notas da extensão de acordes suspensos na melodia, o que ressalta a sonoridade modal da seção, ao mesmo tempo em que são executadas com a figura rítmica da sincopa, característica das tradições musicais brasileiras. Deste modo, ao mesmo tempo em que o grupo se apropria da estética jazzística, ainda mantém-se o caráter rítmico marcante das 'tradições' de sua origem.

0 primeiro acorde da seção (Am7) é o único com terça menor que é utilizado e o fato de sua presença vir logo após o acorde de $\mathrm{Gm} 7$ acentua mais a sonoridade modal da harmonia por utilizar um acorde do mesmo tipo uma $2^{\mathrm{a}} \mathrm{M}$ acima, procedimento comum em músicas de jazz modal.

Todos os outros acordes são dominantes suspensos, ou seja, com nona, sétima menor e quarta justa no lugar da terça, sendo utilizados de maneira predominantemente cromática. Nota-se outro tipo de padrão harmônico nos compassos 6 e 11, onde é utilizada uma mesma frase rítmica para uma similar sequência de acordes, onde o caminho das fundamentais decai um tom e depois um semitom. A ausência de intervalos de quarta e quinta justa nos baixos dos acordes também é um fator que contribui para a construção de uma sonoridade modal na seção.

Tema B

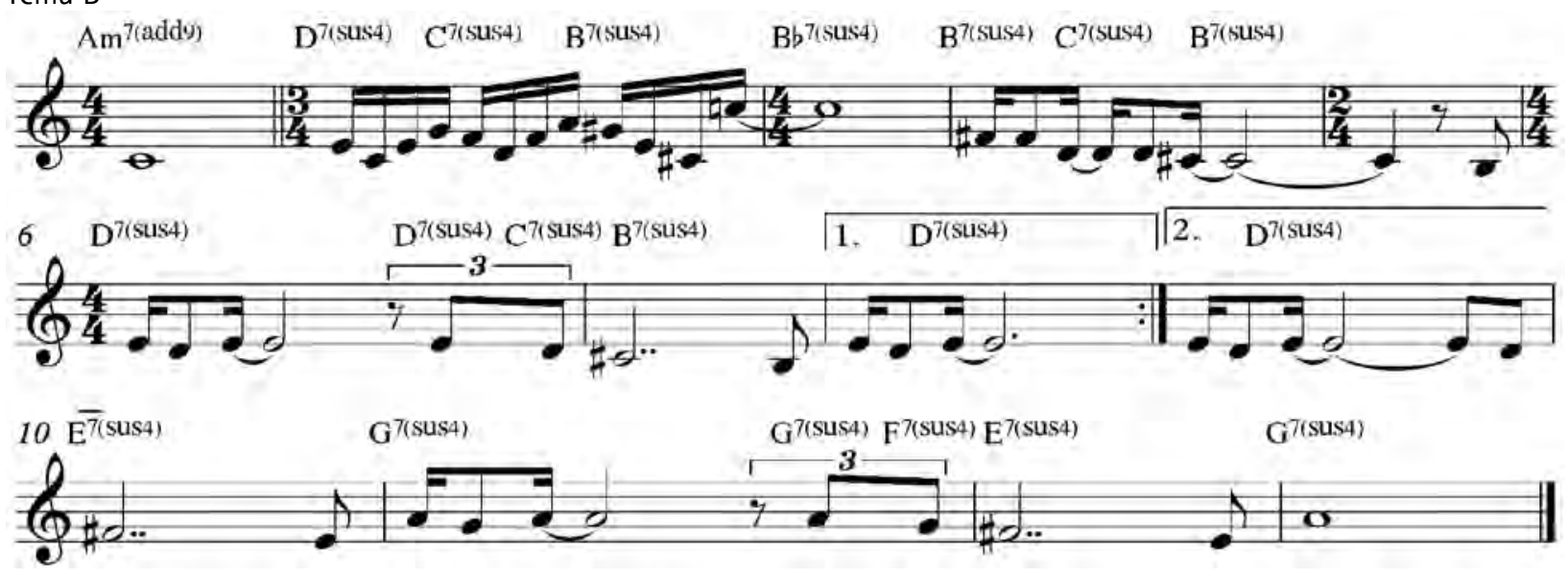

Ex.5 - Melodia e harmonia da seção B de Pé no chão 


\section{7 - Conclusão}

Pudemos demonstrar através das análises algumas maneiras pelas quais o grupo se apropria de elementos musicais de gêneros norte-americanos (como o jazz e rock), ao mesmo tempo preservando características oriundas de gêneros da música brasileira (como a rítmica do samba) na música Pé no chão. Assimilando elementos musicais da estética de um estilo de grande repercussão no mercado, o grupo passa a se alinhar dentro dos padrões de venda internacionais, contando com maior competitividade e distinguindo sua produção dentro do âmbito nacional, através dos elementos "modernos" e considerados de vanguarda incorporados às "raízes brasileiras".

Canclini define em contexto sociológico, o conceito de hibridismo como "processos socioculturais nos quais estruturas ou práticas discretas, que existiam de formas separadas, se combinam para gerar novas estruturas, objetos e práticas" (CANCLINI, 1997, p.XIX). A maneira pela qual as práticas se combinam, "ocorre de modo não planejado, ou é resultado imprevisto de processos migratórios, turísticos e de intercâmbio econômico ou comunicacional". Deste modo, a partir dos influxos da globalização, com a chegada de produtos da indústria cultural norte-americana no Brasil, duas práticas culturais que determinavam estruturas distintas, existiam em formas separadas e em territórios distintos, se combinam na produção do Grupo Medusa e passam a formar novas estruturas, um novo objeto e prática, que caracteriza a sonoridade híbrida do grupo.

Contudo, foi demonstrado no tópico três deste artigo, que existem contradições entre as apropriações de procedimentos musicais estrangeiros realizadas pelo grupo frente ao discurso embasado no ideário nacional- popular presente no primeiro disco. Ainda que o grupo tenha permitido a hibridação, pode-se dizer que seus ideais simbólicos limitaram esses processos, fazendo com que se mantivessem características musicais do território de origem. Assim, o vínculo com a tradição seria então, um elo para sustentar a construção da noção de identidade brasileira e um filtro pelo qual fosse selecionado o que não deveria ser hibridado.

Essa contradição poderia ser fruto do direcionamento da produção do grupo para ambos os segmentos nacionais e internacionais. Segundo Canclini (1997, p.159), "não apenas pelo interesse em expandir o mercado, mas também para legitimar sua hegemonia, os modernizadores precisam persuadir seus destinatários de que - ao mesmo tempo em que renovam a sociedade - prolongam tradições compartilhadas. Posto que pretendem abarcar todos os setores, os projetos modernos se apropriam dos bens históricos e das tradições populares".

A ideia de prolongamento das tradições presente no discurso do grupo se tornaria uma vantagem, pois "o patrimônio cultural se apresenta alheio aos debates sobre a modernidade ele constitui em um recurso menos suspeito para garantir a cumplicidade social" (CANCLINI, 1997, p. 160). Deste modo, a presença de vários elementos da tradição da música brasileira junto do discurso nacional-popular do grupo permite que sejam incorporadas formas culturais estrangeiras símbolos de modernidade, de modo que não fossem contestados por isso. Em vez de reafirmar objetivamente as tradições, caracterizando o território de origem, o Grupo Medusa estabelece um diálogo com formas culturais estrangeiras, enriquece o conhecimento envolvido e ativa uma forma de mediação social entre práticas culturais distintas. 


\section{Referências}

BAHIANA, A. M. Música instrumental: o caminho da improvisação à brasileira. 1979/1980 In: NOVAES, A. Anos 70: Ainda sob a tempestade. (Coletânea) Rio de Janeiro: Aeroplano: Editora Senac Rio, 2005.

CANCLINI, Néstor García. Culturas Hibridas: Estratégias para entrar e sair da Modernidade. São Paulo: EDUSP. Trad. Heloisa P. Cintrão e Ana R. Lessa, 1997.

FREITAS, S. P. R. Espécies de oitavas: usos e significados do termo modo em diferentes práticas teórico-musicais. In: VIII SEMINÁRIO NACIONAL DE PESQUISA EM MÚSICA SEMPEM, 2008, Goiânia. SEMINÁRIO NACIONAL DE PESOUISA EM MÚSICA SEMPEM, 8, 2008, Goiânia. Anais..., 2008. p.257-265.

Teoria da Harmonia na Música Popular: uma definição das relações de combinação entre os acordes na harmonia tonal. São Paulo: Unesp, 1995.

GRIDLEY, Mark C. Jazz Styles: History and Analysis. Englewood Cliffs, N.J.: Prentice-Hall, 1988.

LATORRE, Daniel. Rhodes, a trajetória do piano elétrico. Revista Áudio, música \&t Tecnologia, Rio de Janeiro, edição \#158, novembro. 2004.

MULLER, Daniel Gustavo Mingotti. Música instrumental e indústria fonográfica no Brasil: a experiência do selo som da gente. Campinas: Dissertação de Mestrado em Música - Instituto de Artes UNICAMP, 2005.

NEVES, E. Todos os sons do mundo neste festival de jazz! POP, São Paulo, nº 73, out.1978.

ORTIZ, Renato. A moderna tradição brasileira. São Paulo: Brasiliense, 2006.

PIEDADE, Acácio Tadeu de Camargo. Jazz, música brasileira e fricção de musicalidades. Opus (Porto Alegre), ANPPOM/Ed. da UNICAMP, v. 11, n. 1, p. 113-123, 2005.

ROCCA, Edgard. Ritmos brasileiros e seus instrumentos de percussão. Rio de Janeiro: Escola Brasileira de Música, 1986.

SANDRONI, Carlos. Feitiço Decente: transformações do samba no Rio de Janeiro, 1917-1933. Rio de Janeiro: Jorge Zahar Ed.: Ed. UFRJ, 2001.

SCHOENBERG, Arnold. Fundamentos da composição musical. São Paulo: Edusp, 1991.

SOUZA, T. Rostos e Gostos da Música Popular Brasileira. Porto Alegre: LCtPM, 1979.

\section{Discografia Recomendada}

MEDUSA, Grupo. Grupo Medusa. São Paulo: Som da Gente: 1981.

MEDUSA, Grupo. Ferrovias. São Paulo: Som da Gente: 1983.

\section{Notas}

1 Instrumento inventado pelo americano Harold Rhodes com primeiro protótipo produzido em 1945 após os avanços tecnológicos dos anos 30 , que foram significativos para a indústria musical, inovando pelo emprego de válvulas e pela produção em série. No ano de 1959, Harold faz parceria com Leo Fender para produzir a série Fender Rhodes, com sistema parecido com o de uma guitarra elétrica (LATORRE, 2004). 0 instrumento fez bastante sucesso nas décadas de 60 e 70, sendo amplamente utilizado por pianistas de jazz fusion por conta de sua sonoridade distorcida. Atualmente ainda é bastante utilizado em discos recentes de artistas de jazz.

2 Bluesy é um termo usado para designar uma sonoridade que carrega a utilização da blue note em interpretação de uma frase musical. Segundo o dicionário de jazz GROVE, blue note seria uma terça, sétima ou quinta (menos comum) que tem afinação abaixada em microtons e é utilizada comumente em blues, jazz e músicas relacionadas. Existe muita discussão acerca da origem da blue note, mas acredita-se que ela pode ter sido "descoberta" a partir da dificuldade dos escravos norte-americanos em adaptar a escala pentatônica africana ao diatonismo europeu.

Guilherme Araújo Freire é graduado no curso de Bacharelado em Música Popular pela Universidade Estadual de Campinas e mestrando em Música na mesma instituição desde 2013. Participa do grupo de pesquisa "Música Popular: História, Produção e Linguagem" (CNPq) desde 2010. Atua como músico instrumentista, se apresentando em rodas de choro mensais pelo projeto MusiSAE da Unicamp e em eventos universitários como o "Unicamp de Portas Abertas" (UPA) e 0 "Festival do Instituto de Artes" (FEIA).

Rafael dos Santos é Doutor em Música/Piano pela Universidade de lowa - EUA, sob a orientação do Prof. Daniel Shapiro. É Professor do Departamento de Música, Instituto de Artes da UNICAMP, onde participou da criação do curso de Música Popular. Coordena o Grupo de Pesquisa "Musica Popular: História, Produção e Linguagem" (CNPq). Atua regularmente como solista, arranjador, maestro, compositor e professor. Foi Coordenador do projeto de criação e implantação do Conservatório de Música Popular Cidade de Itajaí, através de Convênio firmado com a Unicamp. É editor da Música Popular em Revista, publicação eletrônica semestral vinculada aos Programas de Pós-Graduação em Música do Instituto de Artes da UNICAMP e do Centro de Letras e artes da UNIRIO 